http://www.jfas.info

\title{
CREATIVITY, THINKING STYLE AND MENTAL DISORDERS
}

\author{
N. Fouladi ${ }^{1}$, E. Shahidi ${ }^{*}, 2$ \\ ${ }^{1}$ PHD Student in Psychology, Department of Psychology, Saveh Branch, Islamic Azad \\ University, Saveh, Iran \\ ${ }^{2} \mathrm{MD}$, Cognitive-Behavioral Psychotherapist, Tolman Institute: Faculty of Specialization in \\ Cognitive-Behavioral Psychotherapy, Palermo-Italy
}

Published online: 16 July 2016

\begin{abstract}
Creativity is considered as a soundand desirable feature. In cognitive approach, it is assumed that human though effects on his behavior. All human's success and progress depends on dynamic, fruitful and effective thinking. As we know, thinking style of people with his attitude and lifestyle. People with pragmatismthinking style are more flexible and show more creativity and innovation than the others and also they have enough skill to plan for unexpected days. Creativity has a significant effect on reduction of anxiety and depression, enhancing of better adaptability, self-efficiency and personal development. Creating and enhancing of creativity in the form of meta-cognitive, character and motivation components can have a high effect on improving mental health, self-efficiency and dealing with mental stress. Creativity can also treat the mental disorders. Today, methods to improvecreativity are a technique to enhance the mental health in the society. In this article, we study the relationship among the creativity, thinking styles and a number of mental disorders.
\end{abstract}

Keywords: Creativity, Thinking Style, Mental Disorder

Author Correspondence, e-mail: dr.enayat.shahidi@gmail.com

doi: http://dx.doi.org/10.4314/jfas.v8i2s.110 


\section{Creativity}

The researchers have presented some different definitions of creativity. Some of them have defined it as a new and useful behavior (Murray and Johnson, 2010). Mednick (1962) has defined the creativity as an ability to combine the related phenomenon in a new and useful way. To Winnicott (1971), creativity is a sign of life and energy (Winnicott 1971; Levine 1992; Mackali et al, 2014). Tusa (2003) has developed creativity vision and defines it as a sign of fiction non-existent thing (Mackali et al, 2014). It can be considered the creativity as a combination of ideas and behaviors that both of them are important for the life. Researches about the creativity and its constituent elements has been began more than a century by social sciences scientists; but the main motivation for the study has been developed by Guidford in 1950. Guidford's creativity with divergent thinking (access to new ways to solve the problems) against the convergent thinking (access to the right answer)is considered similar (Shahrari\&Madanipour, 1996; quoted from Davoudi, 2014). To some researchers like Jameson (1993) and Baroun\&Herinton (1981), creativity is a structure that is a made of emothional and cognitive components (Srivasta et al, 2010). Creativity can be described as a combination of ideas and behaviors that both of them are important for the life (Rybakowski et al. 2008). Creativity is any idea, procedure or product that significantly change the present status (Thys et al. 2013). The effect of dopaminergic neurotransmission has been proposed in creative thinkings and behaviors (De Manzano, 2010; Flaherty, 2011). Kontez (1988) has defined the creativity as the ability of power and realization of new ideas (Sam Khanian, 2002; Davoudi, 2014). According to Freud (1959), the roots of creativity include the conflict in subconscious mind (Id). Sooner or later, unconscious finds a solution to this conflict. Freud tries to meet the physiological needs through attempting to overcome these conflicts; in the other words, creativity is a tension mechanism in this view (Davoudi, 2014). Creative thinking is related to creativity and creating the ideas, steps, experiences and objects. Creativity includes two components: originality (unique or non-unique) and effect (relating to proportionality); both of them are flexible to a certain context. In the other words, creativity involves the discovery, development and creation. It can be said that mental steps that led to an invention, solution or the new combination in any field, are creativity poles and creative thinking. Cognitive features along with creativity include thinking skills such as divergent thinking (Rybakowski et al. 2008).

Gilford (1976) believes that the creativity can be activated and motioned in people through stimulation. He believes that activating must occure in all creativity elements. These elements include divergent components, convergent components and creativity evaluation components 
(Pirkhaefi\&Borjali 2012). In every culture, creativity is kind of cognitive problem-solving orientation that is matched with definition of creativity. Creative person is always ready and presents the creative idea and analyzes it (Lobart 1990, quoted by Alborzi 2014). Tornes (1974), believes that promoting and enhancing of creativity is the mystery of physical and mental survive and it should be included mental and motivational abilities.Amabili (1987) emphasizes on promoting and enhancing of mental abilities, internal motivation and skills in the creativity (Pirkhaefi\&Borjali 2012).

Some researchers make a distinction between outstanding and excellent creativity and ordinary creativity.Ordinary or everyday creativity that is called local creativity is based on the flexibility creativity that helps us to deal with the ever-changing character and the problems of life and find the new solutions for them. It's not still clear whether there is a gap between these two creativities or they are along each other or whether the great creativities (genius creativities) are created due to several ordinary creativities that all human are able to that (Andreasen and Ramchandran,2012).

According to the researchers, it has been shown that enhancing of creativity in people causes enhancing of mental health, better adaptability, increasing of self-efficiency, personal growth, flexibility, optimism and reduction of anxiety and depression. Madjar (2002) states that positive mood has a positive and significant relationship with creativity and innovative action (Hennessey and Amabile, 2010). Paramitha and Indarti(2014), state that internal motivation impacts on the relationship between colleagues and creativity. The studies have shown that positive emotions lead to higher levels of creativity. Most of these researches show that the positive emotions facilitate not only the internal motivation, but also the flexible thinking and problem solution even in the case of difficult tasks (Aspinwall, 1998; Isen, 2005; Hennessey and Amabile, 2010). Also Kaufmann have denied this theory that positive mood facilities the creativity. The other researchers have found that the positive mood does not necessarily increase the divergent thinking, although it reduces the anxiety (Clapham 200; Hennessery and Amabile 2010).

Since the creativity increases self-esteem, motivation and finallyachieving the success, it helps to therapists to treat mental disorders.

\section{Thinking Style}

Thinking styles are the mental frameworks that describe how process of information and ability to solve the problem in the special situations. Generally, the thinkingincludes mental steps that the pictures or some ideas have been experienced in it. 
Strenberg (1997) has called the different methods of information process in people as the thinking style (Farhoosh and Ahmadi 2013). Thinking styles point to people's preferred ways in using the personal abilities. There are three specific ways to recognize a person's thinking style: observing his behaviors when doing works, asking him about how to perceive a person's thinking style and completion one or more psychological questionnaires (Strenberg 1997 quoted by Staky and et al. 2010). Recognizing of thinking styles help people to adapt their thinking to the different thinking styles and at the same time, to be success in their relationships.

It can be possible to change the thinking style. On the other hand, according to the effect of thinking style on behavior and people's activities, managers need to prepare the field for personal and organizational innovation and progress through providing facilities appropriate with everyone's thinking style.Strenberg believes that recognizing people's thinking style is important to expect the choices and job success (Hashemi and et al. 2011). Strenberg (1998) states the success is achieved when people's thinking style is matched with the condition (Hashemi and et al. 2011). Strenberg (1997) with presenting the theory of mental selfgovernment believes that the type of governments on the world is not by accident, most people trend to a style, although this tendency is different according to gob (task) and situation (Farhoosh and Ahmadi 2013). Strenberg (2003) states the thinking style, knowledge, personality and environment effect on creativity. One of man's outstanding characteristics and his main orientation of life is the power of thinking. Atkinson (1998) believes that recognizing the models related to thinking style and motivation for learning is one of basic psychology progress in twentieth century.

In this theory, thirteen thinking styles are described. The styles are distinct in five dimensions: functions, forms, levels, scopes, leaning (Pirmohammadi and et al. 2010).

1- Functions include legislative, executive and judicial style.

2- Forms include hierarchical, monarchic, oligarchic and anarchic style.

3- Levels include global and local thinking style.

4- Scopes include internal and exterior style.

5- Leaning include liberal and conservative (Rafati 2012). 


\begin{tabular}{|c|c|c|}
\hline & Thinking Style & Features \\
\hline \multirow[t]{3}{*}{ Functions } & 1- legislative & $\begin{array}{l}\text { Trend to create, invent, } \\
\text { design and do the things } \\
\text { in their own way }\end{array}$ \\
\hline & 2- executive & Follow the others orders \\
\hline & 3- judicial & $\begin{array}{l}\text { Judge people and } \\
\text { analyze the works }\end{array}$ \\
\hline \multirow[t]{4}{*}{ Forms } & 4- monarchic & $\begin{array}{l}\text { Want to do one thing at } \\
\text { any time }\end{array}$ \\
\hline & 5- hierarchical & $\begin{array}{l}\text { Prefer to do many things } \\
\text { at the same time and } \\
\text { prioritize their tasks }\end{array}$ \\
\hline & 6- oligarchic & $\begin{array}{l}\text { Prefer to do many things } \\
\text { at the same time but } \\
\text { have the problem to } \\
\text { prioritize them }\end{array}$ \\
\hline & 7- anarchic & $\begin{array}{l}\text { Use random methods to } \\
\text { solve problems and } \\
\text { dislike systems, rules, } \\
\text { guidelines and generally } \\
\text { any restrictions }\end{array}$ \\
\hline \multirow[t]{2}{*}{ Levels } & 8- global & $\begin{array}{l}\text { Tend to be involved with } \\
\text { generals and abstract } \\
\text { forms }\end{array}$ \\
\hline & 9- local & $\begin{array}{l}\text { Tend to be involved with } \\
\text { details and objective and } \\
\text { specific examples }\end{array}$ \\
\hline \multirow[t]{2}{*}{ Scopes } & 10- internal & $\begin{array}{l}\text { Tend to work alone, rely } \\
\text { on their own world }\end{array}$ \\
\hline & 11- exterior & $\begin{array}{l}\text { Work with others, rely } \\
\text { on outside world and are } \\
\text { dependent on others }\end{array}$ \\
\hline \multirow[t]{2}{*}{ Leaning } & 12- liberal & $\begin{array}{l}\text { Tend to do things in new } \\
\text { ways; therefore disagree } \\
\text { with customs and fight } \\
\text { with them }\end{array}$ \\
\hline & 13- conservative & $\begin{array}{l}\text { Do things in before } \\
\text { experienced and right } \\
\text { ways and follow the } \\
\text { customs }\end{array}$ \\
\hline
\end{tabular}

The first type of thinking style creates the creativity and demands a higher level of cognitive complexity. This general style includes legal, judicial, hierarchical, general and liberal styles. The second type of thinking style includes those ones that led the person to comply with norm and involves with a lower level of cognitive complexity. This style includes executive, 
local, monarchic and conservative ones. Anarchic, oligarchic, internal and exterior styles make up the third type of thinking style. This style can include the features of first or second styles according to the situation (Farzad and et al. 2007, quoted by Rafati, 2012).

Various researches show that thinking style is related to creativity process, problem solution, making-decision, education progress and etc. and the factors such as culture, sex, age, major, resume, parents' thinking style and etc effect on people's thinking style (Imamipour and Seyf 2003, quoted by Yousefi and Sharif 2010). The researches showed that innovation is related to general thinking. Also Jang (2002) states the creativity has a negative relationship with local thinking. Many researches have studied about the thinking styles related to creativity, for example Wheatley (1997) and Torrance \&Mounad (1979, 1978), Torrance \& Reynolds (1979), Torrance \& Sato (1979), Torrance \& Frostier (1983), Mitchell (1988, 1987), and Brannon \&Feist (1985) have found in many studies that creative people have different thinking style (Sood, 2014).

\section{Mental Disorders}

The empirical evidence for relationship between creativity and psychopathology became apparent in the second half of recent century. For example, the results of two separate studies were reported that kids born from mothers with schizophrenia are more creative than the kids of control group (Heston 1996, Carson 2011 and Karlsson 1970). Mental disorders may be characterized by positive mental creativity, spirituality and resiliency, but unfortunately the positive aspects have been identified as potential results of mental disorders (Galvez, Thommi and Ghaemi 2011). It has been proven that people with outstanding creativity are at higher risk for certain types of psychopathology that include mood disorders, schizophrenia spectrum disorder and alcoholism (Carson 2011). People with creative professions are more treated for mental disorders than the others (Kyaga et al. 2011). In 1980, two studies based on modern diagnostic methods show that outstanding creative people are at higher risk than their less creative counterparts for disorders (Carson 2011). Ludwinghas reported significant rates of psychopathology including mental disorders among artists, musicians, and writers (Carson 2011, Ludwing 1992).

Minor depression for coordination of thoughts and beliefs is an opportunity to create the creativity. Sylvia Plath, Edgar Allan Poe and Emily Dickenson are just a few creative writers who had depression (Thomas and Duke 2007; Fialkoff 2011).

An important characteristic of people with mental disorder is their creativity (Vallarth 2006; Brannon and Feist 2007, quoted from Pirkhaeni and Borjali 20102). There is some evidence for relationship between creativity and psychopathology (Jakovljevic 2013). To studies of 
researchers like Anderson (1987), Richards and et al (1988) and specially Jameson (1993, 1989) on the creativity and psychopathology show their interest in this subject (Mackali et al, 2014). Mental disorder may be along with positive mental traits of creativity, spirituality and flexibility (Galvez, Thommi and Ghaemi, 2011).

Ayzank (1993) has studied the relationship between characteristics and creativity. He considers the mind as a dimension for creativity. He argues that common features between creativity and mental health are more than inclusive cognitive style. This concept refers to the ability to combine very different cognitive elements in an unusual but useful way (Mackali et al, 2014). There are many different samples of artists, musicans and painters who suffer from mental disorder such as Sylvia Plath, Edgar Allan Poe and Emily Dickenson (Thomas and Ducke, 2007; Fialkoff 2011).

Mania and minor forms of it can lead to new ideas; new relationships and increasing contact with the others and in total give a new color to the life. At the same time, minor depression is an opportunity for coordination of thoughts and ideas that the creativity is achieved out of it (Fadai 2009).

To Jameson, there is a very controversial distinction between "normal creativity" and "emotional creativity" associated with bipolar disorder. To Sass, genius creativity or revolutionary creativityis related to schizophrenia. (Thys et al 2012, Jakovljevic 2013).

The relationship between creativity and mental disorder is not yet known. But according to the studies, it can be said that ability to be creative can make person to suffer from mental disorders and mental disorders can help person to be creative. Maybe the creative activities can be a way to cope with challenges and deal with the pains associated with mental disorders.

\section{Role of Creativity in Treatment}

Creativity strengthens the life, frees the human spirit and helps him to cope with mental and physical disabilities. Psychology of creativity is very important to the success of psychiatric treatment. But our knowledge is not still enough about this phenomenon.Many different cultures have accepted this idea that creative expression can significantly contribute to the healing process (Stucky and Nobel 2010). Creativity and mental disorder common genetic vulnerability model suggests that mental disorders may reduce through symptoms of treatment related to vulnerability factors (Carson 2011). 
Today, most psychiatrists and their patients rely on external incentives of clinical pharmacy (pharmacotherapy). Many patients need to external motivation, encouragement and support. This type of incentive treatment is along with success, but full recovery is based on optimal balance of internal and external motivation, creativity and self-regulation. This can be related to significant individual differences in outcome of treatment. In fact, psychotherapy is creative investing that psychiatrist and patients draw new program and different perspective for life, adjust the alternative behaviors and eventually make a new life for their patients. Creativity is associated with the brains that have capacity for goal-oriented motivation, looking for something new and flexible (Flaherty 2011). Patients with bipolar disorder and schizophrenia usually stop taking the drugs. The reason is reduction of creativity and cognitive disorders that occurs as a result of medical treatment (Kyaga et al 2011).

Creative people may prefer to tolerate a higher level of mental disorders rather than changing fewer doses of the drugs that destroy their creativity. They also respond to the behavioral cognitive interventions. People with mood disorders who show creativity, may benefit from creativity treatments such as art, creative writing, theater therapy or music therapy (Carson 2011).

\section{CONCLUSION}

While the creativity is considered as positive personal character, highly creative individuals are at risk of certain types of psychopathology. The relationship between creative people and mental illness has been mentioned since the ancient Greeks. For example, Plato suggested that the poets, philosophers and the play suffer from "Divine Madness" (Jamison, 1993; Carson, 2011). Many studies show a relationship between creativity and bipolar disorder. Creativity may be considered during treatment of bipolar disorder process. Also artists with bipolar disorder or all patients who have art abilities can improve their condition through their art.

There are many techniques of creativity: 1- To determine the goals and objectives, 2motivation, especially inner motivation, 4- stimulating and rewarding to curiosity and discovery, 5- encourage of self-confidence and desire to own interpretation, 6- development of supportable ideas about the creativity, 7-focus on the skills. Therefore every treatment session can be a unique creativity. So showing of certain aspects of mental disorder opens paths to us so that we can have a creative approach to treatment. As well as the creativity, motivation and self-regulation is essential in psychological treatment. As a suggestion for 
future studies can present a study with the subject of compare creativity among bipolar patients with good and poor disease condition and with control of medications and their cognitive problems.

\section{REFERENCES}

- Staky M. Kooshki S. and Vaez E, Relationship between thinking styles and motivation in students' math achievement, Psychological Research Journal, $2^{\text {nd }}$ Year, 2010, 2(93): 105

- Aghayousefi A. Sharif N, Relationship between thinking styles and female high school and pre university students' welfare in north Tehran in 200-2009, psychological studies of Education and Psychology faculty of Al-Zahra University, $6^{\text {th }}$ Year, 2010, 4(85): 104

- Alborzi M, Explanation of the relationship between motivation and creativity with regard to cultural differences, Iranian Cultural Researches Journal, $7^{\text {th }}$ Year, 2014, 1 : 29-49

- Pirkhaefi A. Borjali A, clinical applications of therapeutic creativity model among the students (a new perspective in the field of clinical therapy of mental health), Clinical Psychology Studies Journal, $2^{\text {nd }}$ Year, 2012, 7(77): 96

- Pirmohammadi G. Khodaei A. Yousefi H. Shariati F. Dasta M, Relationship between thinking styles and learning approaches with female and male students' progress, Teaching and Learning Journal (Social and Human Science Journal), $2^{\text {nd }}$ Year, 2010, 1: 69-94

- Rafati M, Study the relationship between thinking styles and learning styles in high school students of Tehran, Humanities and Cultural Studies Institute, $3^{\text {rd }}$ Year, 2012, 2: 63-81

- Farahnoosh M. Ahmadi M, the relationship between thinking styles and learning strategies with progress motivation, Developmental Psychology Journal, Iranian Psychology, $9^{\text {th }}$ Year, 2013, 35: 297-306

- Andreasen, Nancy C. Ramchandran, Kanchna. Creativity in art and science: are there two cultures? Dialogues ClinNeurosci. 2012, 14: 49-54.

- Carson, Shelley. Creativity and psychopathology: A shared vulnerability model. Can J Psychiatry. 2011, 56:144-153. 
- Davoudi, Rasol. AtaeiZanjaniNezhad, Zahra. Relationship between Emotional Intelligence and Creativity of Secondary School Students. EUROPEAN ACADEMIC RESEARCH - 2014, 2(6): 8613- 8627.

- Fadai, Farbod. SadeghHedayat from the "Descriptive Psychiatry" View-Point Iranian Journal of Psychiatry and Behavioral Sciences (IJPBS), 2009, 3(1): 26-19.

- Fialkoff, Michael L. (2011). Depression and Creative Intelligence A Thesis Submitted in Partial Fulfillment of the Requirements for the Degree of Bachelor of Arts With Honors in Psychology from the University of Michigan.

- Flaherty, AW. Brain illnss and creativity: Mechanisms and treatment risks. Can J Psychiatry. 2011, 56(3) :132-143.

- Galvez, Juan Francisco. Thommi, Sairah. Ghaemi, S. Nassir. Positive aspects of mental illness: A review in bipolar disorder. Journal of Affective Disorders 2011, 128:185-190.

- Hennessey, Beth A. Amabile, Teresa M. Creativity Annu Rev. Psychol. 2010, 61:569598.

- Jakovljević, Miro.Creativity, Mental Disorders and Their Treatment:RecoveryOriented Psychopharmacotherapy.PsychiatriaDanubina, 2013; Vol. 25, No. 3, 311315.

- Kyaga, Simon. Lichtenstein, Paul. Boman, Marcus. Hultman, Christina. Langstroem, Niklas. Landen, Mikael. (2011). Creativity and mental disorder: Family study of 300 000 people with severe mental disorder. The British Journal of Psychiatry 199: 373379.

- Mackali, Zeynep. GÜLÖKSÜZ, Sinan. Oral, Timuçin. Creativity and Bipolar Disorder Turkish Journal of Psychiatry 2014, 25: 1-10. 
- Murray, Greg. Johnson, Sheri L. The clinical significance of creativity in bipolar disorder Clinical Psychology Review. 2010, 30: 712-32.

- Paramitha, Anggia. Indarti, Nurul. Impact of the Environment Support on Creativity: Assessing the Mediating Role of Intrinsic Motivation. Procedia - Social and Behavioral Sciences 2014, 115: $102-114$.

- Rybakowski, Janusz. Klonowska, Paulina. Patrzała, Amelia. Jaracz, Jan. Psychopathology and creativity. Archives of Psychiatry and Psychotherapy 2008, 1: $37-47$.

- Sood, Monika Creativity, Stream and Thinking Styles International Educational EJournal 2014, 3: 237-244

- Srivasta, S. Childers ,M.E., Baek,J.HStrong ,C.M., Hill ， S.J.Warsett,K.S., Wang,P.WAkiskal,H.S., Akiskal,K.K\&Ketter,T.A. Toward interaction of affective and cognitive contributors tocreativity in bipolar disorders: : A controlled study. Journal of affectivedisorder 2010, 125, 27-34

- Thys, E. Sabbe, B. Hert, M D. Creativity and psychiatric illness The search for missing link - An historical context for current research. Psychopathology 2013, 46(3):136-144.

- Zhang, LI-FANG. Thinking Styles and models of thinking: implications for education and research. Journal Psychol. 2002, 136(3): 245-261

How to cite this article:

Fouladi N, Shahidi E. Creativity, thinking style and mental disorders. J. Fundam. Appl. Sci., 2016, 8(2S), 1726-1736. 